\title{
Pharmacological Treatment of Apathy in Neurodegenerative Diseases: A Systematic Review
}

\author{
Rosa L. Drijgers ${ }^{a, c}$ Pauline Aalten ${ }^{a, c}$ Ania Winogrodzka ${ }^{b}$ Frans R.J. Verhey ${ }^{a, c}$ \\ Albert F.G. Leentjens ${ }^{a, c}$ \\ Departments of a Psychiatry and ${ }^{\mathrm{b}}$ Neurology, Maastricht University Medical Centre, and ${ }^{\mathrm{c}}$ Alzheimer Center \\ Limburg, Maastricht, The Netherlands
}

\section{Key Words}

Apathy $\cdot$ Neurodegenerative disease $\cdot$ Dementia $\cdot$

Pharmacotherapy $\cdot$ Systematic review

\begin{abstract}
Objective: To evaluate the efficacy of pharmacological treatment of apathy in patients with neurodegenerative diseases. Methods: Systematic review of studies assessing the effects of pharmacological treatment on apathy in neurodegenerative diseases. Results: Thirty-five studies were included: 2 meta-analyses, 13 randomized controlled trials (RCTs), 14 open-label studies, 5 case series, and 1 single case study. Eight studies included apathy as a primary outcome. A cholinesterase inhibitor was investigated in 24 studies, methylphenidate in 5, and other medications in 6 studies. Most RCTs of cholinesterase inhibitors reported a small but statistically significant improvement of apathetic symptoms. Conclusions: Although some medications are promising candidates for further study, there is as yet insufficient evidence that pharmacological treatment improves apathetic symptoms in patients with neurodegenerative disease. Largescale, placebo-controlled RCTs with apathy as a primary outcome measure are needed to establish the potential benefit of pharmacological treatment of apathy.
\end{abstract}

Copyright $\odot 2009$ S. Karger AG, Basel

\section{Introduction}

Apathy is defined as a lack of motivation characterized by diminished goal-oriented behavior and cognition, and diminished emotional concomitant to goal-directed behavior [1]. It is common in neurodegenerative diseases such as Alzheimer's disease (AD) and Parkinson's disease (PD). Apathy is the most frequently reported behavioral syndrome in dementia, with an estimated prevalence of $42-92 \%$ [2-6]. In PD, apathy is reported in $17-70 \%$ of patients [7-10].

Apathy is increasingly considered a distinct syndrome instead of a symptom of neuropsychiatric disorders. Its neuroanatomical and neurochemical substrates are still largely unknown, although limbic structures and striatothalamo-cortical circuits are thought to be involved [11]. Apathy decreases the quality of life of patients with $\mathrm{AD}$ and their caregivers and is associated with caregiver distress; apathy in $\mathrm{AD}$ patients increases the likelihood of institutionalization [12-17]. In patients with PD, apathy is associated with more severe cognitive dysfunction and a decreased ability to perform activities of daily living (ADL) $[8,18-20]$. For these reasons, apathy is increasingly considered a potential target for treatment. Although non-pharmacological interventions have been tested as therapy for apathy - such as multisensory stim-

\section{KARGER}

Fax +4161306 1234 E-Mail karger@karger.ch www.karger.com
Albert F.G. Leentjens

Department of Psychiatry

Maastricht University Medical Centre, PO Box 5800

NL-6202 AZ Maastricht (The Netherlands)

Tel. +31 43387 7443, Fax +31 43387 5444, E-Mail a.leentjens@np.unimaas.nl 
Table 1. Levels of evidence and grades of recommendation

\begin{tabular}{ll}
\hline Level & Explanation \\
\hline $\begin{array}{l}\text { Levels of evidence } \\
1\end{array}$ & $\begin{array}{l}\text { One or more randomized controlled trials (RCT) (or sys- } \\
\text { tematic review of trials) of sufficient size to ensure a low risk } \\
\text { of false-positive or false-negative results (narrow confi- } \\
\text { dence interval) }\end{array}$ \\
\hline 2 & $\begin{array}{l}\text { Good quality cohort studies or low-quality RCT (e.g. too } \\
\text { small, <80\% follow-up) }\end{array}$ \\
\hline 3 & $\begin{array}{l}\text { Case-control studies, including systematic reviews of case- } \\
\text { control studies }\end{array}$ \\
\hline 4 & $\begin{array}{l}\text { Case series, and poor-quality cohort and case-control stud- } \\
\text { ies }\end{array}$ \\
\hline 5 & $\begin{array}{l}\text { Expert opinion without explicit critical appraisal, or based } \\
\text { on physiology, bench research, or 'first principles' }\end{array}$ \\
\hline Grades/strengths of recommendations \\
Consistent level 1 studies
\end{tabular}

Summarized from Oxford Centre for Evidence-Based Medicine 2001 [25].

ulation, protocollized activity therapy, communication therapy, and massage therapy - to date, results have been either inconclusive or negative [21-24]. However, the pharmacological treatment of apathy has not yet been critically evaluated. Therefore, the aim of this study is to systematically review the evidence for pharmacological treatment of apathy in patients with neurodegenerative diseases.

\section{Methods}

Search Strategy and Selection Criteria

The Pubmed database was searched up to June 2008 using the keyword 'apathy', applying the following limits: 'humans', 'clinical trial', 'meta-analysis', 'practice guideline', and 'randomized controlled trial'. Abstracts of the retrieved articles were screened for relevance. Criteria for inclusion in the review were: (i) the study population involved patients with a neurodegenerative disease; (ii) the study objective was to evaluate the effects of a pharmacological treatment; (iii) apathy was reported as a primary or secondary outcome; and (iv) the article was written in English,
Dutch, German, or French. Further articles for inclusion were identified by searching the references of retrieved articles and by checking the Cochrane library. There were no limitations regarding study design, and thus the review included meta-analyses, randomized controlled trials (RCTs), open-label studies, and case studies. Studies that were included in a meta-analysis were not also included separately as RCTs.

All articles were read in full and their level of evidence and outcome were assessed by 2 of the authors (R.D., A.W.). If there was a difference of opinion, a consensus meeting was held with the last author (A.L.) to discuss the disagreement and to reach a final decision. Studies were classified by their level of evidence following the system of the Oxford Centre for Evidence-Based Medicine $[25,26]$. Grades of recommendation were also scored with this classification (table 1).

\section{Results}

\section{Literature Search}

The initial search yielded 136 articles. Of these, 23 articles were selected on basis of title and abstract and the remainder were excluded because the study population did not suffer from a neurodegenerative disease $(n=46)$, the study did not investigate pharmacotherapy $(n=59)$, or the article was written in a language other than English, German, French or Dutch $(n=8)$. Another 32 potentially relevant articles were identified from the references of the included articles, 19 of which were excluded because the study population did not suffer from a neurodegenerative disease $(n=1)$, the study did not investigate a pharmacological intervention $(n=2)$, or apathy was not a primary or secondary outcome $(n=16)$. Three studies known by the authors, but not retrieved by the search, were also included. Four studies were not considered individually because they were included in 2 meta-analyses. In total, 35 studies were included in the review.

\section{Appraisal of Studies}

Of these 35 studies, only 9 had the treatment of apathy in a neurodegenerative disease as primary outcome, whereas the other 26 studies included apathy as a secondary outcome variable, often as part of a broader measure of neuropsychiatric symptoms, such as the Neuropsychiatric Inventory (NPI) [27]. The review included 2 metaanalyses, 13 RCTs, 14 open-label studies, and 6 case studies. Cholinesterase inhibitors were investigated in 24 studies, methylphenidate in 5 studies, and other drugs (paroxetine, amantadine, memantine, levodopa, tianeptine, and Ginkgo biloba extract) in 6 studies (1 study each). Both meta-analyses, 9 of the 13 RCTs, and 9 of the 14 open-label studies involved patients with $\mathrm{AD}$; the other 
studies included patients with dementia with Lewy bodies (DLB) $(\mathrm{n}=3)$, frontotemporal dementia (FTD) $(\mathrm{n}=4)$, vascular dementia $(\mathrm{n}=2)$, and PD $(\mathrm{n}=3)$. Two studies included both patients with $\mathrm{AD}$ and vascular dementia, and 1 study did not define the type of dementia (table 2).

Study recommendations were graded according to the criteria of the Oxford Centre for Evidence-Based Medicine (table 1) [25], and where possible, effect sizes were calculated with Cohen's d [28]. Both meta-analyses and 11 of the 13 RCTs were classified as grade A. None of these studies included apathy as a primary outcome variable. The remaining 2 RCTs were classified as grade $B$, and the open-label studies and the case studies were classified as grade $\mathrm{C}$ (table 2).

\section{Meta-Analyses}

Cummings et al. [29] performed a meta-analysis of the combined data from 2 previously published double-blind, multicenter, placebo-controlled RCTs involving 672 patients treated with the cholinesterase inhibitor metrifonate $[30,31]$. After 26 weeks, treatment with metrifonate (30 or $60 \mathrm{mg}$ daily) resulted in a significant reduction in the average score on the NPI apathy item $(\mathrm{p}=0.019)$, with $51 \%$ of the metrifonate-treated versus $36 \%$ of the placebotreated patients achieving a reduction of at least $30 \%(\mathrm{p}=$ 0.020).

Herrmann and colleagues [32] performed a metaanalysis of 3 large placebo-controlled RCTs examining the effectiveness of the cholinesterase inhibitor galantamine. Two of these trials had been published before [33, 34]. The meta-analysis included 2,033 patients with mild to moderate $\mathrm{AD}$ treated for 13,22 , or 26 weeks with doses varying from 16-32 mg daily. Apathy was assessed, as a secondary outcome variable, using the NPI apathy item. There was no significant difference in outcome between treatment with galantamine or placebo.

\section{RCTs}

Thirteen RCTs assessed the effects of pharmacological treatment on apathy, of which 1 evaluated apathy as a primary outcome, measured with the Apathy Evaluation Scale (AES) $[35,36]$. The other 12 studies included apathy as a secondary outcome, mostly measured with the NPI apathy item. Seltzer et al. [37] used another validated scale, the Apathy Scale (AS), to measure apathy as a secondary outcome [38]. Ten studies involved a cholinesterase inhibitor, 1 study involved methylphenidate, 1 paroxetine, and 1 Ginkgo biloba extract. Of the cholinesterase inhibitors, donepezil was used in 6 studies, metrifonate in 2 , and galantamine and rivastigmine in 1 each.
Donepezil was the most-studied cholinesterase inhibitor. Feldman et al. [39] reported that donepezil produced a significantly greater reduction in NPI apathy score than placebo in 290 patients with $\mathrm{AD}$ but failed to report the p value. The same database was used for 2 sub-analyses [40, 41]. Gauthier et al. [41] included the same 290 patients and found significant treatment differences on the NPI apathy score ( $p=0.0018)$, whereas Feldman et al. [40] found a significant improvement in NPI apathy score with donepezil in 145 patients with more severe AD $(\mathrm{p}=$ 0.012 ), operationalized as a score between 5 and 12 on the Mini Mental State Examination (MMSE) [42]. Tariot et al. [43] did not find donepezil to improve apathy (assessed using the NPI apathy item) in 208 nursing home patients with $\mathrm{AD}$, whereas Holmes et al. [44] reported a significant reduction in NPI apathy score after 12 weeks of open-label treatment with donepezil in 134 patients with AD $(p<0.001)$. No results were reported for the subsequent randomization phase. Seltzer et al. [37] found no difference in scores on the AS between treatment with donepezil and placebo in 253 patients with AD.

Kaufer [45] and Dubois et al. [46] both studied the effect of metrifonate in patients with AD. The former reported a significant improvement in apathy (NPI apathy item) in 408 patients treated with metrifonate compared with placebo ( $\mathrm{p}=0.03)$ [45], whereas in the latter study $(\mathrm{n}=605)$, a significant improvement $(\mathrm{p}=0.048$, compared with placebo) in the NPI apathy score of patients treated with a high $(60-80 \mathrm{mg})$ but not low $(40-50 \mathrm{mg})$ dose of metrifonate was reported [46].

Of the other pharmacological treatments, McKeith et al. [47] reported an improvement in NPI apathy score after 23 weeks of treatment with rivastigmine (6-12 mg) in 120 patients with DLB; however, no $p$ value was mentioned. Erkinjuntti et al. [48] reported that galantamine significantly improved the NPI apathy score of 592 patients with vascular dementia $(\mathrm{p}<0.0001)$. In a recent study, Herrmann et al. [35] found methylphenidate (10 mg, b.i.d.) to improve apathy (measured with the AES) compared with placebo in 13 apathetic patients with AD. In their study of 10 patients with FTD, Deakin et al. [49] defined a NPI- 4 score to measure apathy based on factor analysis of the full NPI. This NPI-4 score represented a sub-score consisting of the items disinhibition, apathy, aberrant motor behavior and euphoria. The authors did not find paroxetine to significantly improve apathy compared with placebo [49]. A study by Scripnikov et al. [50] examined the effects of Ginkgo biloba extract (EGb 761) in 400 patients with vascular dementia and AD. One of the largest drug-placebo differences in favor of EGb 761 


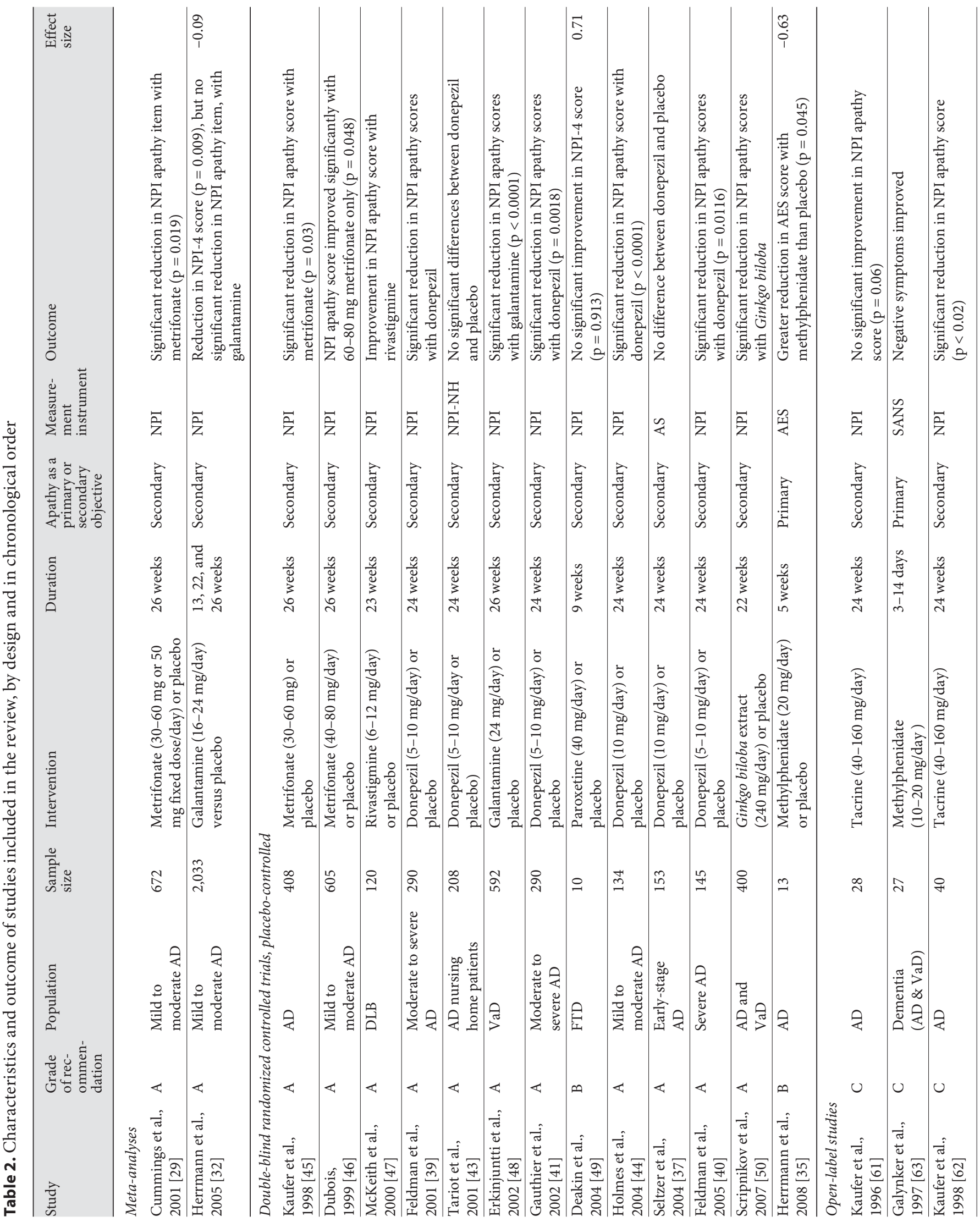




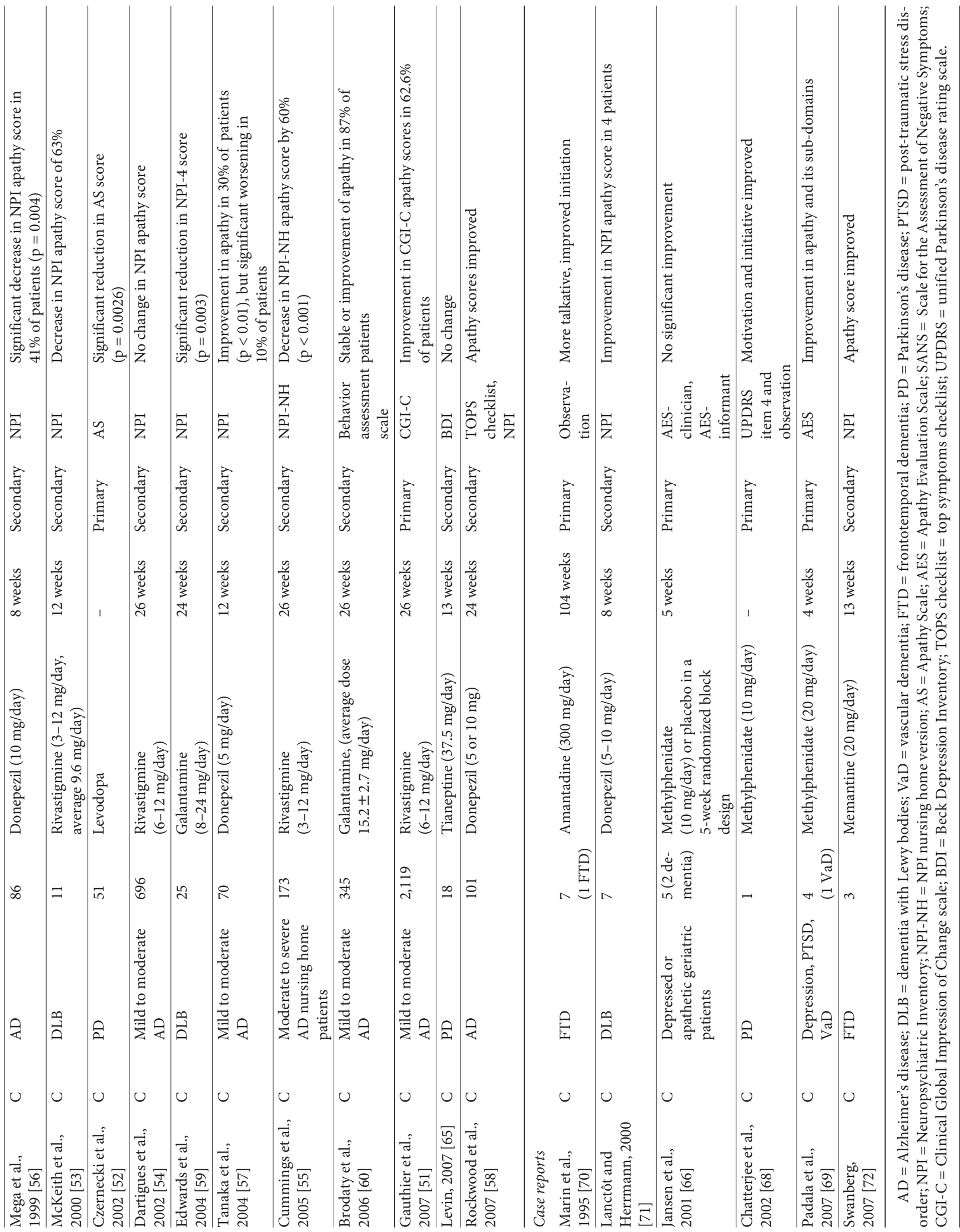


was found for the NPI apathy score, but the significance level was not reported.

\section{Open-Label Studies}

Fourteen open-label studies were retrieved, of which 9 included patients with $\mathrm{AD}$; the other 5 studies included patients with $\mathrm{DLB}, \mathrm{PD}$, and both $\mathrm{AD}$ and vascular dementia. The studies of Gauthier et al. [51] and Czernecki et al. [52] included apathy as a primary outcome variable, measured with the Clinical Global Impression of Change scale (CGI-C) and the AS, respectively. Eleven studies used a cholinesterase inhibitor: rivastigmine $(n=4)$, donepezil $(\mathrm{n}=3)$, galantamine $(\mathrm{n}=2)$, and tacrine $(\mathrm{n}=$ 2). The remaining 3 open-label studies used methylphenidate, levodopa therapy, and tianeptine, 1 each respectively.

Of the studies investigating rivastigmine, McKeith et al. [53] reported a $63 \%$ reduction in the NPI apathy score of 11 patients with DLB, and Dartigues et al. [54] $(n=696)$ reported a significant improvement in NPI apathy score after 12 weeks ( $\mathrm{p}=0.011$ ) but not after 6 months of treatment. Cummings et al. [55] found a 60\% improvement in NPI apathy score in 173 patients with $\mathrm{AD}(\mathrm{p}<0.001)$, and Gauthier et al. [51] found that $62.6 \%$ of 2,119 patients with $\mathrm{AD}$ showed improvement of apathy, measured as primary outcome with the CGI-C.

Donepezil was investigated in 3 open-label studies. Mega et al. [56] reported a significant improvement in apathy in $41 \%$ of 86 patients with $\mathrm{AD}$ and apathy ( $\mathrm{p}=$ 0.004). While Tanaka et al. [57] reported that $30 \%$ of 70 patients with $\mathrm{AD}$ showed an improvement in total NPI score and the NPI apathy score after donepezil treatment ( $p<0.01$ ), apathy became significantly worse in $10 \%$ of the patients. Rockwood et al. [58] $(\mathrm{n}=101)$ reported that donepezil consistently improved apathy, but these authors failed to mention the significance of the finding.

Two open-label studies examined the effect of galantamine. Edwards et al. [59] examined 25 patients with DLB and observed a significant improvement in the scores of a NPI-4 subscale, which included delusions, hallucinations, apathy, and depression $(\mathrm{p}=0.003)$. Brodaty et al. [60] reported that 6 months of galantamine treatment stabilized or improved the apathy scores of $87 \%$ of 345 patients with $\mathrm{AD}$.

Kaufer et al. [61, 62] investigated tacrine in 2 open-label studies involving patients with AD. In the first study $(\mathrm{n}=28)$, apathy, as measured with the NPI, was one of the most responsive symptoms, although the improvement did not reach statistical significance $(p=0.06)$ [61]. In the second study, in which 28 of the 40 patients came from the previous study, a significant reduction in NPI apathy score was detected $(p<0.02)$. Apathy improved equally in patients with mild, moderate, or severe dementia [62]. In a pilot study, Galynker et al. [63] investigated the effect of methylphenidate on negative symptoms, including apathy, in 27 patients with $\mathrm{AD}$ or vascular dementia. Negative symptoms were measured with the Scale for the Assessment of Negative Symptoms (SANS) [64]. Results showed that the negative symptoms of patients with dementia appeared to be responsive to treatment with methylphenidate [63]. Czernecki et al. [52] studied the effects of levodopa on motivation in non-demented, non-depressed patients with $\mathrm{PD}$ with response fluctuations, comparing patients in 'on' and 'off' states to controls and using the AS to measure apathy. While patients with PD were apathetic, their apathy responded to levodopa treatment ( $p=0.0026$ ). Levin [65] focused on the use of tianeptine in 18 patients with PD. While core symptoms of depression measured with the Beck Depression Inventory improved, those of apathy did not.

\section{Case Studies}

Six case studies investigated the effect of pharmacological treatment of apathy, of which 3 studies focused on methylphenidate. Notable was that 4 studies assessed apathy as a primary outcome. The patients had various neurodegenerative diseases, including $\mathrm{PD}$, (vascular) dementia, FTD, DLB, and AD. Jansen et al. [66] used the AES as outcome measure for apathy and reported a treatmentassociated improvement in AES-clinician score and AESinformant score; however, the improvements were not significant ( $\mathrm{p}=0.077$ and $\mathrm{p}=0.086$, respectively). Chatterjee and Fahn [68] studied methylphenidate in 1 patient with PD, measuring apathy with item 4 (motivation/initiative) of part I of the UPDRS [67]. They found methylphenidate to improve motivation/initiative, with scores decreasing from 3 to 0 ( $0=$ none; $4=$ complete loss of motivation). Padala and colleagues [69] reported an improvement in apathy (AES scores) of $18.3 \%$ in a patient with vascular dementia. One case, part of a series involving patients with apathy, reported that amantadine, in combination with bupropion or levodopa, improved observed initiative and communication (the patient became more talkative) in a man with frontal lobe dementia [70]. Lanctôt and Herrmann [71] studied the effects of treatment with donepezil on neuropsychiatric symptoms in 7 patients with DLB, of which 4 patients showed an improvement in NPI apathy score. A case series of 3 patients with FTD using memantine reported an improvement in NPI apathy score [72]. 


\section{Discussion}

This is the first systematic review of the pharmacological treatment of apathy in patients with neurodegenerative diseases. Of the 35 articles included, 2 meta-analyses and 11 RCTs provided grade A evidence, and 2 RCTs provided grade $\mathrm{B}$ evidence. The grading of quality was based on the general design and methodology of the studies. However, apathy was a primary outcome in only 1 RCT. From this it may be concluded that there is a lack of high-quality research that focuses specifically on apathy.

Among pharmacological treatments, cholinesterase inhibitors have been studied the most. Of the 2 metaanalyses, 1 reported positive (metrifonate) and the other (galantamine) reported no effects of these agents on apathy. Of the 9 RCTs with cholinesterase inhibitors, 3 derived from the same trial [39-41] and another 2 derived from the same study $[61,62]$. Six studies reported positive effects (metrifonate, galantamine, and donepezil), 2 no effect (donepezil), and 2 did not report on the significance of their findings (rivastigmine, donepezil). Of the 11 open-label studies with cholinesterase inhibitors, 5 reported a significant improvement in apathy, while 6 reported inconsistent effects or did not report the significance of the findings. Given the lack of a placebo condition, an open-label design is not the most appropriate for studying the effects of drugs on apathy. Many of the included articles did not contain enough information to calculate the size of the effect on apathy, and for those that did, the effect sizes were small, which makes the clinical relevance of the effects doubtful. This is in line with a review of the treatment of neuropsychiatric symptoms of dementia by Sink et al. [73], who also concluded that effect sizes were mostly modest and that positive effects on neuropsychiatric symptoms were trivial.

Concerning the other drugs that were used apart from cholinesterase inhibitors, a single RCT provided evidence for a positive effect of Ginkgo biloba extract, and 1 small RCT and 3 case reports suggested that methylphenidate was beneficial. No conclusions could be drawn about the other medications investigated. Taken together, the metaanalyses and RCTs with cholinesterase inhibitors yielded inconclusive results so that it is not possible to draw firm conclusions about the efficacy of cholinesterase inhibitors for the treatment of symptoms of apathy in patients with neurodegenerative diseases. However, several studies provided some promising indications, in particular, for the effectiveness of cholinesterase inhibitors and methylphenidate, although this needs thorough investi- gation in the future. These results are in line with the conclusion of Boyle and Malloy [3], who stated that cholinesterase inhibitors reduce the neuropsychiatric symptoms of $\mathrm{AD}$, with apathy showing the most consistent improvement, and that other activating neuropsychotropic agents may be useful in the treatment of apathy.

This review had several limitations. The first is that the conclusions drawn necessarily depend on the quality of the studies included. Although apathy is a common symptom of many neurodegenerative diseases, few RCTs have investigated apathy as a primary outcome. Most studies have focused on cognitive deterioration, with apathy as a secondary outcome, or on neuropsychiatric symptoms in a broad sense as measured by the NPI, with apathy being one of several outcome variables investigated. For identifying the effectiveness of the interventions, the studies used 2 different types of ratings. Some used a composite measure of frequency and severity, such as the NPI, while others have used scales that only rate severity, such as the AES [36]. How this differential approach influences the outcome of the studies is not known. In addition, in the absence of generally accepted diagnostic criteria, most of the rating instruments used in the studies have not been validated in this specific population. Studies focusing on apathy as a primary outcome were generally case studies; only 1 small RCT focused on apathy as primary outcome [35]. Moreover, most of these studies involved patients with $\mathrm{AD}$, varying widely in disease stage and severity. From earlier research, it is known that apathy is correlated with the severity of cognitive problems in community-based older adults [16]. In dementia, the occurrence and severity of apathy increase with disease severity and persist during the more advances stages of dementia [6]. The role of disease severity in treatment response of apathetic symptoms is as yet unknown, but some studies have reported differential responses in different severity stages [62]. Studies of pharmacological treatment of apathy in other neurodegenerative diseases were under-represented. Many of the studies included were small, lacked a control group, and did not control for concomitant psychotropic medication. In some studies, apathy was part of a cluster of several NPI items, yet the validity of such an 'apathy' cluster is unclear. All these issues make a generalization of the results questionable.

Another limitation is that our results may have been influenced by publication bias. We retrieved only studies that explicitly reported apathy. While many studies have used the NPI, scores on NPI sub-items are usually only reported if there is a general effect on the NPI. This may 
have led to non-retrieval of negative studies, with a consequent overestimation of the effect of pharmacological treatment.

In this systematic review, we evaluated the evidence base for pharmacological treatment of apathy in patients with neurodegenerative diseases. We found limited and inconsistent evidence for the efficacy of any specific drug in treating apathy in these patients and hence could not draw firm conclusions about their efficacy. Although research is hampered by the lack of generally accepted criteria for apathy as a syndrome [74], cholinesterase inhibitors and methylphenidate may be the best candidates for further study. Future research should include high-quality RCTs with apathy as a primary outcome. To facilitate this research, reliable and validated diagnostic criteria for apathy and validated scales that differentiate between ap- athy, depression, and executive dysfunction are a prerequisite. In addition, studies need to address different individual neurodegenerative diseases to be able to generalize results to other forms of dementia. Moreover, studies should take potential differences in treatment response between patients with different severity stages of disease into consideration. Study of the potential of pharmacological treatment of apathy in neurodegenerative disease is warranted because effective treatment would improve the quality of life of both patients and their caregivers.

\section{Acknowledgement}

This study was sponsored in part by the Stichting Internationaal Parkinson Fonds.

\section{References}

1 Starkstein SE, Leentjens AFG: The nosological position of apathy in clinical practice. J Neurol Neurosurg Psychiatry 2008;79:10881092.

-2 Mega MS, Cummings JL, Fiorello T, Gornbein J: The spectrum of behavioral changes in Alzheimer's disease. Neurology 1996;46: 130-135.

3 Boyle PA, Malloy PF: Treating apathy in Alzheimer's disease. Dement Geriatr Cogn Disord 2004;17:91-99.

-4 Landes AM, Sperry SD, Strauss ME, Geldmacher DS: Apathy in Alzheimer's disease. J Am Geriatr Soc 2001;49:1700-1707.

5 Steinberg M, Shao H, Zandi P, Lyketsos CG Welsh-Bohmer KA, Norton MC, Breitner JC, Steffens DC, Tschanz JT; Cache County Investigators: Point and 5-year period prevalence of neuropsychiatric symptoms in dementia: the Cache County Study. Int J Geriatr Psychiatry 2008;23:170-177.

-6 Aalten P, de Vugt ME, Jaspers N, Jolles J, Verhey FRJ: The course of neuropsychiatric symptoms in dementia. Part I: findings from the two-year longitudinal Maasbed study. Int J Geriatr Psychiatry 2005;20:523-530.

7 Dujardin K, Sockeel P, Devos D, Delliaux M, Krystkowiak P, Destee A, Defebvre L: Characteristics of apathy in Parkinson's disease. Mov Disord, 2007;22:778-784.

8 Pluck GC, Brown RG: Apathy in Parkinson's disease. J Neurol Neurosurg Psychiatry 2002; 73:636-642.

\9 Sockeel P, Dujardin K, Devos D, Deneve C, Destee A, Defebvre L: The Lille apathy rating scale (LARS), a new instrument for detecting and quantifying apathy: validation in Parkinson's disease. J Neurol Neurosurg Psychiatry 2006;77:579-584.
10 Leentjens A, Dujardin K, Marsh L, Martinez-Martin P, Richard I, Starkstein S, Weintraub D, Sampaio C, Poewe W, Rascol O, Stebbins G, Goetz C: Apathy and anhedonia rating scales in Parkinson's disease: critique and recommendations. Mov Disord 2008; 23:2004-2014

11 Brown RG, Pluck G: Negative symptoms: the 'pathology' of motivation and goal-directed behaviour. Trends Neurosci 2000;23:412417.

12 Finkel S: The significance of the behavioural and psychological symptoms of dementia. Clinician 1998;16:33-42.

13 Chan DC, Kasper JD, Black BS, Rabins PV: Presence of behavioral and psychological symptoms predicts nursing home placement in community-dwelling elders with cognitive impairment in univariate but not multivariate analysis. J Gerontol A Biol Sci Med Sci 2003;58:548-554.

14 Shin I, Carter M, Masterman D, Fairbanks L, Cummings JL: Neuropsychiatric symptoms and quality of life in Alzheimer disease. Am J Geriatr Psychiatry 2005;13:469-474.

15 de Vugt ME, Stevens F, Aalten P, Lousberg R, Jaspers N, Winkers I, Jolles J, Verhey FR: Behavioural disturbances in dementia patients and quality of the marital relationship. Int J Geriatr Psychiatry 2003;18:149-154.

16 Onyike CU, Sheppard JM, Tschanz JT, Norton MC, Green RC, Steinberg M, WelshBohmer KA, Breitner JC, Lyketsos CG: Epidemiology of apathy in older adults: the Cache County Study. Am J Geriatr Psychiatry 2007;15:365-375.

17 Yeager C, Hyer L: Apathy in dementia: relations with depression, functional competence, and quality of life. Psychol Rep 2008; 102:718-722.
18 Aarsland D, Larsen J, Lim N, Janvin C, Karlsen K, Tandberg E, Cummings J: Range of neuropsychiatric disturbances in patients with Parkinson's disease. J Neurol Neurosurg Psychiatry 1999;67:492-496.

19 Levy M, Cummings J, Fairbanks L, Masterman D, Miller B, Craig AH, Paulsen JS, Litvan I: Apathy is not depression. J Neuropsychiatry Clin Neurosci 1998;10:314-319.

20 Isella V, Melzi P, Grimaldi M, Iurlaro S, Piolti R, Ferrarese C, Frattola L, Appollonio I: Clinical, neuropsychological, and morphometric correlates of apathy in Parkinson's disease. Mov Disord 2002;17:366-371.

21 Politis AM, Vozzella S, Mayer LS, Onyike CU, Baker AS, Lyketsos CG: A randomized, controlled, clinical trial of activity therapy for apathy in patients with dementia residing in long-term care. Int J Geriatr Psychiatry 2004;19:1087-1094.

22 Chapman S, Weiner M, Rackley A, Hynan L, Zientz J: Effects of cognitive-communication stimulation for Alzheimer's disease patients treated with donepezil. J Speech Lang Hear Res 2004;47:1149-1163.

23 Chung J, Lai C, Chung P, French H: Snoezelen for dementia. Cochrane Database Syst Rev 2002;4:CD003152.

24 Hirakawa Y, Masuda Y, Kimata T: Effects of home massage rehabilitation therapy for the bed-ridden elderly: a pilot trial with a threemonth follow-up. Clinical Rehabilitation 2005;19:20-27.

25 Medicine OCfE-b: Levels of evidence and grades of recommendation. Oxford Centre for Evidence-Based Medicine. http://www. cebm.net/levels_of_evidence (May, 2001).

26 Phillips B, Ball C, Badenoch D, Straus S, Haynes B, Dawes M: Levels of evidence. BJU International 2008;101:932. 
-27 Cummings JL, Mega, M, Gray K, RosenbergThompson S, Carusi DA, Gornbein J: The Neuropsychiatric Inventory: comprehensive assessment of psychopathology in dementia. Neurology 1994;44:2308-2314.

28 Cohen J: Statistical Power Analysis for the Behavioral Sciences. Hillsdale, Lawrence Earlbaum Associates, 1988.

-29 Cummings JL, Nadal A, Masterman D, Cyrus P: Efficacy of metrifonate in improving the psychiatric and behavioral disturbances of patients with Alzheimer's disease. J Geriatr Psychiatry Neurol 2001;14:101108.

-30 Morris J, Cyrus P, Orazem J, Mas J, Bieber F, Ruzicka B, Gulanski B: Metrifonate benefits cognitive, behavioral, and global function in patients with Alzheimer's disease. Neurology 1998;50:1222-1230.

-31 Raskind M, Cyrus P, Ruzicka B, Gulanski B: The effects of metrifonate on the cognitive, behavioural, and funtional performance of Alzheimer's disease patients. J Clin Psychiatry 1999;60:318-325.

>32 Herrmann N, Rabheru K, Wang J, Binder C: Galantamine treatment of problematic behavior in Alzheimer's disease: post-hoc analysis of pooled data from three large trials. Am J Geriatr Psychiatry 2005;13:527-534.

\33 Rockwood K, Mintzer J, Truyen L, Wessel T, Wilkinson D: Effects of a flexible galantamine dose in Alzheimer's disease: a randomized, controlled trial. J Neurol Neurosurg Psychiatry 2001;71:589-595.

$\checkmark 34$ Tariot P, Solomon PR, Morris JC, Kershaw P, Lilienfeld S, Ding C: A 5-month, randomized, placebo-controlled trial of galantamine in AD. The Galantamine USA-10 Study Group. Neurology 2000;54:2269-2276.

-35 Herrmann N, Rothenburg LS, Black SE, Ryan M, Liu BA, Busto UE, Lanctot KL: Methylphenidate for the treatment of apathy in Alzheimer disease. J Clin Psychopharmacol 2008;28:296-301.

-36 Marin RS, Biedrzycki RC, Firinciogullari S: Reliability and validity of the Apathy Evaluation Scale. Psychiatry Res 1991;38:143-162.

-37 Seltzer B, Zolnouni P, Nunez M, Goldman R, Kumar D, Ieni J, Richardson S: Efficacy of donepezil in early-stage Alzheimer disease. Arch Neurol 2004;61:1852-1856.

-38 Starkstein SE, Mayberg HS, Preziosi TJ, Andrezejewski P, Leiguarda R, Robinson RG: Reliability, validity, and clinical correlates of apathy in Parkinson's disease. J Neuropsychiatry Clin Neurosci 1992;4:134-139.

>39 Feldman H, Gauthier S, Hecker J, Vellas B, Subbiah P, Whalen E: A 24-week, randomized, double-blind study of donepezil in moderate to severe Alzheimer's disease. Neurology 2001;57:613-620.
40 Feldman H, Gauthier S, Hecker J, Vellas B, Xu Y, Ieni J, Schwam E: Efficacy and safety of donepezil in patients with more severe Alzheimer's disease: a subgroup analysis from a randomized placebo-controlled trial. Int J Geriatr Psychiatry 2005;20:559-569.

41 Gauthier S, Feldman H, Hecker J, Vellas B, Ames D, Subbiah P, Whalen E, Emir B: Efficacy of donepezil on behavioral symptoms in patients with moderate to severe Alzheimer's disease. Int Psychogeriatr 2002;14:389404.

42 Folstein M, Folstein S, McHugh P: 'Minimental state'. A practical method for grading the cognitive state of patients for the clinician. J Psychiatr Res 1975;12:189-198.

43 Tariot P, Cummings JL, Katz IR, Mintzer J, Perdomo C, Schwam E: A randomized, double-blind, placebo-controlled study of the efficacy and safety of donepezil in patients with Alzheimer's disease in the nursing home setting. J Am Geriatr Soc 2001;49: 1590-1599.

44 Holmes C, Wilkinson D, Dean C, Vethanayagam S, Olivieri S, Langley A: The efficacy of donepezil in the treatment of neuropsychiatric symptoms in Alzheimer disease. Neurology 2004;63:214-219.

45 Kaufer D: Beyond the cholinergic hypothesis: the effect of metrifonate and other cholinesterase inhibitors on neuropsychiatric symptoms in Alzheimer's disease. Dement Geriatr Cogn Disord 1998;9:8-14.

-46 Dubois B, McKeith I, Orgogozo J, Collins O, Meulien D: A multicentre, randomized, double-blind, placebo-controlled study to evaluate the efficacy, tolerability and safety of two doses of metrifonate in patients with mild-to-moderate Alzheimer's disease: the MALT study. Int J Geriatr Psychiatry 1999; 14:973-982.

47 McKeith I, Del Ser T, Spano P, Emre M, Wesnes K, Anand R, Cicin-Sain A, Ferrera R, Spiegel R: Efficacy of rivastigmine in dementia with Lewy bodies: a randomized, double-blind, placebo-controlled international study. Lancet 2000;356:2031-2036.

48 Erkinjuntii T, Kurz A, Gauthier S: Efficacy of galantamine in probable vascular dementia and Alzheimer's disease combined with cerebrovascular disease: a randomized trial. Lancet 2002;359:1283-1290.

49 Deakin JB, Rahman S, Nestor PJ, Hodges JR, Sahakian BJ: Paroxetine does not improve symptoms and impairs cognition in frontotemporal dementia: a double-blind randomized controlled trial. Psychopharmacology 2004;172:400-408.

50 Scripnikov A, Khomenko A, Napryenyenko O: Effects of Ginkgo biloba extract EGb 761 on neuropsychiatric symptoms of dementia: findings from a randomized controlled trial. Wien Med Wochenschr 2007;157:295-300.
1 Gauthier S, Juby A, Rehel B, Schecter R: EX$\mathrm{ACT}$ : rivastigmine improves high prevalence of attention deficits and mood and behaviour symptoms in Alzheimer's disease. Int J Clin Pract 2007;61:886-895.

52 Czernecki V, Pillon B, Houeto JL, Pochon JB, Levy R, Dubois B: Motivation, reward, and Parkinson's disease: influence of dopatherapy. Neuropsychologia 2002;40:2257-2267.

53 McKeith I, Crace J, Walker Z, Byrne E, Wilkinson D, Stevens T, Perry E: Rivastigmine in the treatment of dementia with Lewy bodies: preliminary findings from an open trial. Int J Geriatr Psychiatry 2000;15:387392.

-54 Dartigues J, Goulley F, Bourdeix I, Pere J, Barberger-Gateau P: Rivastigmine in current clinical practice in patients with mild to moderate Alzheimer's disease. Rev Neurol 2002;158:807-812

55 Cummings JL, Koumaras B, Chen M, Mirski D: Effects of rivastigmine treatment on the neuropsychiatric and behavioral disturbances of nursing home residents with moderate to severe probable Alzheimer's disease: a 26-week, multicenter, open-label study. Am J Geriatr Psychiatry 2005;3:137-148.

56 Mega M, Masterman D, O’Connor S, Barclay T, Cummings JL: The spectrum of behavioral responses to cholinesterase inhibitor therapy in Alzheimer disease. Arch Neurol 1999;56:1388-1393.

57 Tanaka M, Namiki C, Thuy D, Yoshida H, Kawasaki K, Hashikawa K: Prediction of psychiatric response to donepezil in patients with mild to moderate Alzheimer's disease. J Neurol Sci 2004;225:135-141.

58 Rockwood K, Black S, Bedard M, Tran T, Lussier I; TOPS Study Investigators: Specific symptomatic changes following donepezil treatment of Alzheimer's disease: a multicentre, primary care, open-label study. Int J Geriatr Psychiatry 2007;22:312-319.

-59 Edwards K, Hershey L, Wray L, Bednarczyk E, Lichter D, Farlow M, Johnson S: Efficacy and safety of galantamine in patients with dementia with Lewy bodies: a 12-week interim analysis. Dement Geriatr Cogn Disord 2004;17:40-48.

60 Brodaty H, Woodward M, Barnes N, Allen G: A naturalistic study of galantamine for Alzheimer's disease. CNS Drugs 2006;20: 935-943.

-61 Kaufer D, Cummings JL, Christine D: Effect of tacrine on behavioral symptoms in Alzheimer's disease: an open-label study. J Geriatr Psychiatry Neurol 1996;9:1-6.

62 Kaufer D, Cummings JL, Christine D: Differential neuropsychiatric symptom response to tacrine in Alzheimer's disease: relationship to dementia severity. J Neuropsychiatry Clin Neurosci 1998;10:55-63. 
63 Galynker I, Ieronimo C, Miner C, Rosenblum J, Vilkas N, Rosenthal R: Methylphenidate treatment of negative symptoms in patients with dementia. J Neuropsychiatry Clin Neurosci 1997;9:231-239.

64 Andreasen N: Scale for the Assesment of Negative Symptoms (SANS). Iowa City, University of Iowa, 1983.

-65 Levin O: Coaxil (tianeptine) in the treatment of depression in Parkinson's disease. Neurosci Behav Physiol 2007;37:419-424.

66 Jansen IH, Olde Rikkert MG, Hulsbos HA, Hoefnagels WH: Toward individualized evidence-based medicine: five ' $\mathrm{N}$ of 1' trials of methylphenidate in geriatric patients. J Am Geriatr Soc 2001;49:474-476.
67 Fahn S, Elton RL: Unified Parkinson's Disease Rating Scale. Florham Park, McMillan Health Care Information, New Jersey, 1987.

68 Chatterjee A, Fahn S: Methylphenidate treats apathy in Parkinson's disease. J Neuropsychiatry Clin Neurosci 2002;14:461-462.

69 Padala R, Burke WJ, Bhatia SC, Petty F: Treatment of apathy with methylphenidate. JNeuropsychiatry Clin Neurosci 2007;19:8183.

770 Marin RS, Fogel BS, Hawkins J, Duffy J, Krupp B: Apathy: a treatable syndrome. J Neuropsychiatry Clin Neurosci 1995;7:2330.

71 Lanctot KL, Herrmann N: Donepezil for behavioural disorders associated with Lewy bodies: a case series. Int J Geriatr Psychiatry 2000;15:338-345.
72 Swanberg M: Memantine for behavioral disturbances in frontotemporal dementia, a case series. Alzheimer Dis Assoc Disord 2007;21:164-166.

73 Sink KM, Holden KF, Yaffe K: Pharmacological treatment of neuropsychiatric symptoms of dementia, a review of the evidence. JAMA 2005;293:596-608.

74 Robert PH, Onyike CU, Leentjes AFG, Dujardin K, Aalten P, Starkstein SE, Verhey FR, Yessavage J, Clement JP, Drapier D, Bayle F, Benoit M, Boyer P, Lorca PM, Thibaut F, Gauthier S, Grossberg G, Vellas B, Byrne J: Proposed diagnostic criteria for apathy in Alzheimer's disease and other neuropsychiatric disorders. Eur Psychiatry 2009;24:98104 . 